\title{
Fermentative Polyhydroxybutyrate Production from a Novel Feedstock Derived from Bakery Waste
}

\author{
Daniel Pleissner, ${ }^{1}$ Wan Chi Lam, ${ }^{1}$ Wei Han, ${ }^{1}$ Kin Yan Lau, ${ }^{1}$ \\ Lai Chun Cheung, ${ }^{2}$ Ming Wui Lee, ${ }^{2}$ Ho Man Lei, ${ }^{2}$ Kin Yu Lo, ${ }^{2}$ Wai Yee $\mathrm{Ng}^{2}$ Zheng Sun, ${ }^{1,3}$ \\ Mehmet Melikoglu, ${ }^{4}$ and Carol Sze Ki Lin ${ }^{1}$ \\ ${ }^{1}$ School of Energy and Environment, City University of Hong Kong, Tat Chee Avenue, Kowloon, Hong Kong \\ ${ }^{2}$ Department of Chemical and Biomolecular Engineering, Hong Kong University of Science and Technology, \\ Clear Water Bay, Kowloon, Hong Kong \\ ${ }^{3}$ College of Fisheries and Life Science, Shanghai Ocean University, Shanghai 201306, China \\ ${ }^{4}$ Department of Chemical Engineering, Gebze Institute of Technology, 41400 Gebze, Kocaeli, Turkey
}

Correspondence should be addressed to Carol Sze Ki Lin; carollin@cityu.edu.hk

Received 17 February 2014; Revised 19 May 2014; Accepted 30 June 2014; Published 20 July 2014

Academic Editor: Ramkrishna Sen

Copyright (c) 2014 Daniel Pleissner et al. This is an open access article distributed under the Creative Commons Attribution License, which permits unrestricted use, distribution, and reproduction in any medium, provided the original work is properly cited.

\begin{abstract}
In this study, Halomonas boliviensis was cultivated on bakery waste hydrolysate and seawater in batch and fed-batch cultures for polyhydroxybutyrate (PHB) production. Results demonstrated that bakery waste hydrolysate and seawater could be efficiently utilized by Halomonas boliviensis while PHB contents between 10 and $30 \%(\mathrm{w} / \mathrm{w})$ were obtained. Furthermore, three methods for bakery waste hydrolysis were investigated for feedstock preparation. These include: (1) use of crude enzyme extracts from Aspergillus awamori, (2) Aspergillus awamori solid mashes, and (3) commercial glucoamylase. In the first method, the resultant free amino nitrogen (FAN) concentration in hydrolysates was 150 and $250 \mathrm{mg} \mathrm{L}^{-1}$ after 20 hours at enzyme-to-solid ratios of 6.9 and $13.1 \mathrm{U} \mathrm{g}^{-1}$, respectively. In both cases, the final glucose concentration was around $130-150 \mathrm{~g} \mathrm{~L}^{-1}$. In the second method, the resultant FAN and glucose concentrations were $250 \mathrm{mg} \mathrm{L}^{-1}$ and $150 \mathrm{~g} \mathrm{~L}^{-1}$, respectively. In the third method, highest glucose and lowest FAN concentrations of $170-200 \mathrm{~g} \mathrm{~L}^{-1}$ and $100 \mathrm{mg} \mathrm{L}^{-1}$, respectively, were obtained in hydrolysates after only 5 hours. The present work has generated promising information contributing to the sustainable production of bioplastic using bakery waste hydrolysate.
\end{abstract}

\section{Introduction}

The natural polymer polyhydroxybutyrate (PHB) belongs to the group of polyhydroxyalkanoates and is synthesized by over 75 different genera of bacteria as intracellular carbon and energy storage compound [1]. Similar chemical properties to polypropylene [2] and its biodegradability make PHB a potential sustainable alternative to petroleum-based plastics. Moreover, PHB is nontoxic and highly biocompatible with mammalian cells, tissues, and organs and, thus, applicable as biomaterial in tissue engineering for surgical implants and scaffolds, biodegradable screws and staples, and wound dressings [3]. Consequently, much effort has been made to produce $\mathrm{PHB}$ at industrial scale in an economical and feasible way. Several bacterial strains such as Alcaligenes latus, Azotobacter vinelandii, Cupriavidus necator (formerly classified as Wautersia eutropha), and recombinant Escherichia coli were investigated as PHB producers with high productivities [412]. Furthermore, Halomonas boliviensis, a bacterium which is able to accumulate more than $80 \%(\mathrm{w} / \mathrm{w})$ of its biomass as PHB under high salt conditions, was investigated [9]. However, fermentative PHB production in large-scale with these bacteria is cost-inefficient, as glucose, commonly used as carbon source, accounts for approximately $30 \%$ of the total production costs [13].

In Hong Kong, over 3,500 tonnes of industrial, commercial, and domestic food wastes are generated daily $[14,15]$. These food wastes are rich in starch and proteins, which 
could serve as a source of glucose and amino acids after hydrolysis. Our group previously has demonstrated that food waste hydrolysate could serve as a nutrient source to various microorganisms [15-18]. Therefore, utilization of organic wastes as nutrient, particularly as carbon sources, could be an option to reduce fermentation costs. Also, it would contribute to the development of an economically feasible industrial PHB production. Furthermore, in order to create a cost-efficient fermentation medium, Lin et al. [19] reported the use of seawater as a natural mineral and sustainable water source. Recently, three hydrolytic approaches for the recovery of nutrients from food waste have been reported, which include (1) the use of commercial glucoamylases [20, 21]; (2) solid fungal mashes of Aspergillus awamori and/or Aspergillus oryzae [15-17, 22]; and (3) crude enzyme extract from Aspergillus awamori and/or Aspergillus oryzae [18, 23, 24]. However, there is lack of systematic studies concerning the efficiency of hydrolytic approaches for the recovery of nutrients from food waste.

In this study, we aim to provide an adaptation strategy on methods that could lead to efficient production of fermentation feedstock in presence of seawater for sustainable production of PHB. Firstly, hydrolyzed bakery waste and seawater were investigated as fermentation feedstock and medium, respectively, for $\mathrm{PHB}$ production in batch and fed-batch cultures of Halomonas boliviensis. Secondly, the efficiency of glucose and free amino nitrogen (FAN) productions from bakery waste using three hydrolytic approaches: (1) crude enzyme extract from Aspergillus awamori, (2) commercial glucoamylase, and (3) Aspergillus awamori solid mashes were compared.

\section{Materials and Methods}

2.1. Handling of Bakery Waste. The material used for the production of hydrolysate was out-of-date bakery waste (pastry and cake) obtained from a Starbucks store located in Shatin, Hong Kong. Bakery waste was homogenized immediately after collection by a kitchen blender and stored at $4^{\circ} \mathrm{C}$.

2.2. Microorganisms. Aspergillus awamori (ATCC 14331) was purchased from the American Type Culture Collection (Rockville, MD, USA) and used for fungal solid mashes and crude enzyme extract production.

Spore suspension of Aspergillus awamori was prepared by spore extraction with $10 \%(\mathrm{w} / \mathrm{v})$ glycerol from a culture grown for 7 days at $30^{\circ} \mathrm{C}$ on $1.5 \%(\mathrm{w} / \mathrm{v})$ corn meal agar. Counting of spores was carried out using a haemocytometer.

Halomonas boliviensis BAA-759 was purchased from the American Type Culture Collection (Rockville, MD, USA) and stored in cryopreservation vials at $-80^{\circ} \mathrm{C}$ until used in fermentation. Inocula for fermentative $\mathrm{PHB}$ production were grown in $250 \mathrm{~mL}$ shake flasks containing $100 \mathrm{~mL}$ defined medium consisting of $10 \mathrm{~g} \mathrm{~L}^{-1}$ glucose, $2 \mathrm{~g} \mathrm{~L}^{-1}$ yeast extract, $40 \mathrm{gL}^{-1} \mathrm{NaCl}, 0.75 \mathrm{gL}^{-1} \mathrm{KCl}, 0.38 \mathrm{gL}^{-1} \mathrm{MgSO}_{4} \times 7 \mathrm{H}_{2} \mathrm{O}$, $0.2 \mathrm{~g} \mathrm{~L}^{-1} \mathrm{NaBr}$, and $0.13 \mathrm{~g} \mathrm{~L}^{-1} \mathrm{CaCl}_{2} \times 2 \mathrm{H}_{2} \mathrm{O}$ for 24 hours at $35^{\circ} \mathrm{C}$ and an initial $\mathrm{pH}$ value of 7.5 [25]. Shake flasks were agitated at $200 \mathrm{rpm}$ by an orbital shaker.
2.3. Mineral Concentration of Seawater. Mineral concentration was determined after evaporation of a known volume of seawater.

2.4. Fermentative Polyhydroxybutyrate Production. Fermentative $\mathrm{PHB}$ production by Halomonas boliviensis in batch and fed-batch cultures was performed using bakery waste hydrolysate at $35^{\circ} \mathrm{C}$ and $\mathrm{pH}$ 7.5. The $\mathrm{pH}$ was automatically controlled by the addition of $2 \mathrm{M} \mathrm{NaOH}$ and $2 \mathrm{M} \mathrm{H}_{2} \mathrm{SO}_{4}$. Stirring speed was set between 850 and 1,300 rpm in order to maintain dissolved oxygen above $20 \%$. Antifoam was added manually when needed. A $2 \%(\mathrm{v} / \mathrm{v})$ inoculum was used in all fermentations. Samples for quantification of glucose, fructose, FAN, and biomass concentrations as well as weight specific $\mathrm{PHB}$ content were taken regularly, centrifuged at $11,000 \times \mathrm{g}$ for 10 minutes, and stored at $-80^{\circ} \mathrm{C}$. Bakery waste hydrolysate used in batch cultures was prepared as described by Pleissner et al. [16] in seawater with a mineral concentration of $29.7 \mathrm{~g} \mathrm{~L}^{-1}$. Bakery waste hydrolysate used in fed-batch cultures was concentrated by water evaporation using a rotary evaporator.

2.5. Quantification of Glucose, Fructose, and Free Amino Nitrogen. Glucose and fructose were analyzed using high performance liquid chromatography (Waters, UK) by injection of $10 \mu \mathrm{L}$ of supernatant on an Aminex HPX-87H column (Bio-Rad, USA) and eluted isocratically with $5 \mathrm{mM} \mathrm{H}_{2} \mathrm{SO}_{4}$ at $0.5 \mathrm{~mL} \mathrm{~min} \mathrm{~m}^{-1}$ and $65^{\circ} \mathrm{C}$. Detection was performed by a refractive index detector (Waters, $\mathrm{UK}$ ) at $35^{\circ} \mathrm{C}$.

Free amino nitrogen (FAN) concentration was measured based on the ninhydrin reaction method as described by Lie [26]. Glycine was used as reference compound.

2.6. Biomass Concentration. Biomass concentration of Halomonas boliviensis was measured as cell dry weight after centrifugation of a known volume of culture broth at $11,000 \times \mathrm{g}$ for 10 minutes and lyophilization of the pellet.

2.7. Polyhydroxybutyrate Extraction, Esterification, and Quantification. Extraction and esterification of PHB from freezedried biomass of Halomonas boliviensis was carried out according to the method of Riis and Mai [27]. To $0.02 \mathrm{~g}$ of freeze dried biomass, $2 \mathrm{~mL}$ dichloroethane, $2 \mathrm{~mL}$ acidified propanol (propanol: $\mathrm{HCl}, 4: 1, \mathrm{v} / \mathrm{v}$ ), and $0.2 \mathrm{~mL}$ benzoic acid were added and the mixture was incubated for two hours at $100^{\circ} \mathrm{C}$. After chilling to room temperature, $4 \mathrm{~mL}$ of demineralised water was added and the suspension was mixed. The organic phase was recovered after mixing.

Quantification of extracted PHB was performed by injection of $1 \mu \mathrm{L}$ of the recovered organic phase on an Agilent PoraPLOT Q-HT (USA) column connected to a gas chromatography system (Hewlett Packard 6890 GC System, USA). Detection was carried out using a flame ionization detector with helium as carrier gas. Following temperature programme was used: initial temperature $90^{\circ} \mathrm{C}$ held for 2 minutes then increased to $150^{\circ} \mathrm{C}$ at a rate of $8^{\circ} \mathrm{C}$ minute and held for 4 minutes and finally increased to $280^{\circ} \mathrm{C}$ at $20^{\circ} \mathrm{C}$ minute ${ }^{-1}$ and held for 1 minute. The retention time and 
peak area were compared to standards (PHB and benzoic acid) of known concentration.

2.8. Aspergillus awamori Solid Mashes. For preparation of Aspergillus awamori solid mashes, $10-15 \mathrm{~g}$ of wet bakery waste (7-10.5 g dry weight) was placed in a petri dish and inoculated with $5 \times 10^{5}$ spores per gram wet waste. The fungal mashes were incubated for 7 to 8 days at $30^{\circ} \mathrm{C}$.

2.9. Crude Enzyme Extract. Crude enzyme extract from Aspergillus awamori was prepared by homogenizing 7 to 8 days old fungal solid mashes from three petri dishes thoroughly in a kitchen blender containing $30 \mathrm{~mL}$ demineralized water. Afterwards, additional $30 \mathrm{~mL}$ demineralized water was added into the blender and the mixture was stirred at $30^{\circ} \mathrm{C}$ for 30 minutes followed by centrifugation at $5,500 \times \mathrm{g}$ for 10 minutes. Crude enzyme extract refers to the obtained supernatant after filtration with Whitman number 1 filter paper.

2.10. Commercial Glucoamylase. Commercial glucoamylase (Glucose Amylase) was provided by Shandong Longda Bioproducts, Co., Ltd., China.

2.11. Glycolytic Activity Assay. Glycolytic activity of the crude enzyme extract from Aspergillus awamori and commercial glucoamylase was determined using the method described previously [23]. One unit (U) of glycolytic activity is defined as the amount of enzyme that releases $1 \mu \mathrm{mol}$ of glucose per minute at $\mathrm{pH} 5.5$ and $55^{\circ} \mathrm{C}$.

2.12. Proteolytic Activity Assay. Proteolytic activity of the crude enzyme extract was quantified using a modified version of the method described by Wang et al. [28] based on the formation of FAN after hydrolyzing $0.6 \%(\mathrm{w} / \mathrm{v})$ casein solubilized in $0.2 \mathrm{M}$ potassium phosphate buffer ( $\mathrm{pH} 7.5)$. Enzymatic hydrolysis was performed by adding $0.25 \mathrm{~mL}$ of crude enzyme extract to $0.5 \mathrm{~mL}$ casein solution. The reaction mixture was then incubated at $55^{\circ} \mathrm{C}$ for 30 minutes and terminated by adding $0.25 \mathrm{~mL}$ of $10 \%(\mathrm{w} / \mathrm{v})$ trichloroacetic acid (TCA). The concentration of FAN released from casein was quantified based on nynhidrin reaction method described in Section 2.5. One unit of protease activity (U) was defined as the production of $1 \mu \mathrm{g}$ FAN by $1 \mathrm{~mL}$ crude enzyme extract in one minute under reaction conditions.

2.13. Investigation of Bakery Waste Hydrolysis. Hydrolysis of $548.8 \mathrm{~g}$ (dry weight) homogenized bakery waste was conducted with one of the following methods: (1) crude enzyme extract from Aspergillus awamori solid mashes from three petri dishes; (2) commercial glucoamylase added in a ratio of 6.9 and $13.1 \mathrm{U}$ per gram dry bakery waste; and (3) Aspergillus awamori solid mashes from three petri dishes in demineralized water. Different enzyme-to-solid ratios were used to investigate the opportunity to adjust glucose and FAN concentrations in hydrolysates. Hydrolysis was carried out at $55^{\circ} \mathrm{C}$ and $\mathrm{pH} 4-4.5$. A solid-to-liquid ratio, defined as the ratio of dry weight (g) to liquid (mL) [22], of 38 to $47 \%$ (w/v) was used in all hydrolyses. In addition, a control experiment without addition of enzymes or fungal biomass was carried out under the same experimental conditions. Samples of $1.2 \mathrm{~mL}$ were taken at regular intervals and immediately mixed with $350 \mu \mathrm{L} 10 \%$ (w/v) TCA in order to deactivate enzymes and to prevent further hydrolysis. Quantification of glucose and FAN in supernatant was performed after centrifugation of the sample-TCA mixture at $11,000 \times \mathrm{g}$ for 10 minutes.

Independently, seawater was investigated as medium in hydrolysis. To $330 \mathrm{~g}$ (dry weight) homogenized bakery waste, $1 \mathrm{Ug}^{-1}$ of a commercial glucoamylase was added and the hydrolysis was carried out at $55^{\circ} \mathrm{C}$ and $\mathrm{pH} 4-4.5$ in seawater with a mineral concentration of $29.7 \mathrm{~g} \mathrm{~L}^{-1}$.

2.14. Composition of Bakery Waste. Quantification of carbohydrate, nitrogen, and protein contents in bakery waste was performed in duplicate as described in Pleissner et al. [16]. All specific contents of waste constituents reported in this study are based on dry weights. Quantification of soluble and insoluble fractions of carbohydrates, nitrogen, and proteins was carried out in a control experiment described in Section 2.13. The soluble fraction of carbohydrates, nitrogen, and proteins in bakery waste refers to the fraction that was solubilized in water, while the insoluble fraction of each waste constituent refers to the fraction that was not soluble in water.

\section{Results and Discussion}

3.1. Fermentative Polyhydroxybutyrate Production. The feasibility of using bakery waste hydrolysate and seawater as medium for fermentative PHB production with Halomonas boliviensis was examined. Figure 1(a) shows the fermentation of Halomonas boliviensis on hydrolyzed bakery waste and seawater at initial glucose and FAN concentrations of $50.5 \mathrm{~g} \mathrm{~L}^{-1}$ and $172.2 \mathrm{mg} \mathrm{L}^{-1}$, respectively. After 30 hours, the FAN concentration was reduced to $32 \mathrm{mg} \mathrm{L}^{-1}$ and the $\mathrm{PHB}$ content increased to $14 \%(\mathrm{w} / \mathrm{w})$ due to nitrogen limitation of Halomonas boliviensis cells. When glucose concentration became below $5 \mathrm{~g} \mathrm{~L}^{-1}$, a hydrolysate consisting of $103.0 \mathrm{~g} \mathrm{~L}^{-1}$ glucose and $606.2 \mathrm{mg} \mathrm{L}^{-1}$ FAN was fed continuously at a rate of $0.029 \mathrm{~L} \mathrm{~h}^{-1}$ for 20 hours in order to prevent glucose depletion. During fed-batch phase, cells consumed all the glucose $(59.7 \mathrm{~g}$ ) and FAN (351.6 mg) supplied. The feeding resulted in a further increase in biomass concentration from 5 to $25 \mathrm{~g} \mathrm{~L}^{-1}$ due to the supply of glucose and FAN in excess. The PHB content of cells, however, remained unchanged at 10-14\% (Table 1).

A second fermentation was conducted similar to the first fermentation. The FAN concentration of the hydrolysate used throughout fed-batch phase, however, was much lower in order to limit biomass formation and to facilitate PHB accumulation (Figure 1(b)). For the initial batch phase, a cake rich bakery waste hydrolysate consisting of $62.5 \mathrm{~g} \mathrm{~L}^{-1}, 20.0 \mathrm{~g} \mathrm{~L}^{-1}$, and $197.2 \mathrm{mg} \mathrm{L}^{-1}$ glucose, fructose, and FAN, respectively, was used (Figure $1(\mathrm{~b})$ ). FAN was rapidly consumed within 20 hours and the PHB concentration consequently increased to $32.3 \%(\mathrm{w} / \mathrm{w})$ between 20 and 30 hours of fermentation. 
TABLE 1: PHB fermentations by Halomonas boliviensis using bakery waste hydrolysate and defined medium using glucose and xylose as carbon sources.

\begin{tabular}{|c|c|c|c|c|c|}
\hline Medium & Process & $\begin{array}{c}\text { PHB content } \\
{[\%, \mathrm{w} / \mathrm{w}]}\end{array}$ & $\begin{array}{c}\text { PHB } \\
\text { concentration } \\
{\left[\mathrm{g} \mathrm{L}^{-1}\right]}\end{array}$ & $\begin{array}{c}\text { Yield of PHB } \\
{\left[\mathrm{mol} \mathrm{PHB} \mathrm{mol}^{-1}\right.} \\
\text { carbon substrate] }\end{array}$ & References \\
\hline \multirow{4}{*}{$\begin{array}{l}\text { Bakery waste } \\
\text { hydrolysate }\end{array}$} & Batch & 13.7 & 1.1 & 0.16 & \multirow{4}{*}{ This study } \\
\hline & Fed-batch & 9.3 & 2.4 & 0.23 & \\
\hline & Batch & 32.3 & 2.6 & 0.17 & \\
\hline & Fed-batch & 25.2 & 2.1 & 0.33 & \\
\hline Glucose & Fed-batch & 81 & 35.4 & 0.13 & [9] \\
\hline Glucose/xylose & Batch & $44.9 \pm 0.41$ & 1.0 & 0.24 & [11] \\
\hline Glucose & Batch & 55 & 0.5 & 0.13 & [29] \\
\hline
\end{tabular}
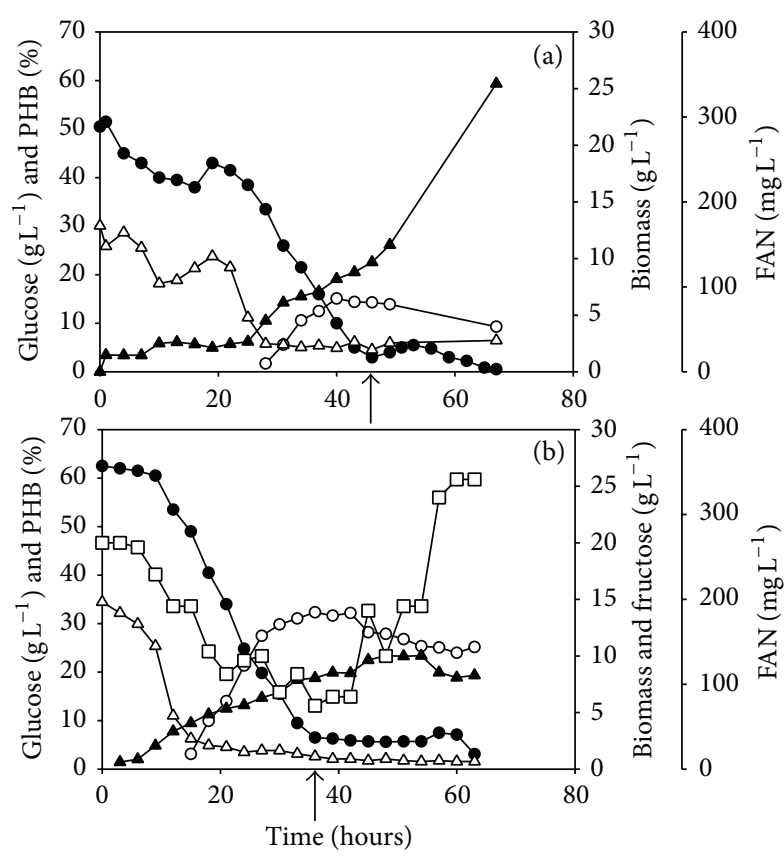

FIgURE 1: Fermentative PHB production. Profile of glucose (closed circle), fructose (open square), free amino nitrogen (FAN, open triangle), and biomass (closed triangle) concentrations as well as weight specific PHB content (open circle) during fermentation of Halomonas boliviensis on bakery waste hydrolysate ((a) and (b)). Fermentations were initially performed as batch cultures and later changed to fed-batch cultures. Start of feeding is indicated by an arrow.

During batch phase, around $10 \mathrm{gL}^{-1}$ biomass was formed and a simultaneous consumption of glucose and fructose was observed. After 38 hours, when glucose concentration was below $5 \mathrm{~g} \mathrm{~L}^{-1}$, a cake rich bakery waste hydrolysate consisting of $67.0 \mathrm{~g} \mathrm{~L}^{-1}$ glucose and $29.6 \mathrm{~g} \mathrm{~L}^{-1}$ fructose, but only $79.9 \mathrm{mg} \mathrm{L}^{-1}$ FAN was fed continuously at a rate of $0.034 \mathrm{~L} \mathrm{~h}^{-1}$ for 24 hours. During fed-batch phase, cells consumed around $54.7 \mathrm{~g}$ glucose and $65.2 \mathrm{mg}$ FAN. In comparison to the first fermentation, the use of a hydrolysate with a lower FAN concentration limited the formation of biomass. However, the PHB content was not further increased during fedbatch phase and $25.2 \mathrm{mg} \mathrm{g}^{-1} \mathrm{PHB}$ was found after continuous feeding (Figure 1(b) and Table 1). Fructose, as an additional carbon source, was not consumed during fed-batch and its concentration increased to more than $25 \mathrm{~g} \mathrm{~L}^{-1}$.

Generally, the molar yield of $\mathrm{PHB}$ was two times higher in fed-batch cultures compared to batch cultures, while the PHB content did not change (Figure 1 and Table 1). Based on the data reported for batch cultures of Halomonas boliviensis using defined media and glucose [29], and glucose and xylose [11] as carbon sources, yields of 0.13 and $0.24 \mathrm{~mol} \mathrm{PHB} \mathrm{mol}^{-1}$ carbon substrate, respectively, were calculated. These yields are comparable to the yields (0.16 and $0.17 \mathrm{~mol} \mathrm{PHB} \mathrm{mol}^{-1}$ carbon substrate, Table 1) obtained in batch cultures in this study using food waste hydrolysate. The conversion yield during fed-batch phase of the first fermentation was $0.23 \mathrm{~mol} \mathrm{PHB} \mathrm{mol}^{-1}$ carbon substrate (Table 1 and Figure 1(a)) which is similar to the yield obtained in batch phase due to the formation of biomass. However, in the second fermentation when the amount of nitrogen in feed hydrolysate was reduced, formation of biomass was limited while the molar yield of PHB increased to $0.33 \mathrm{~mol} \mathrm{PHB} \mathrm{mol}{ }^{-1}$ carbon substrate. This yield is considerably higher than the yield found in batch phase $\left(0.17 \mathrm{~mol} \mathrm{PHB} \mathrm{mol}^{-1}\right.$ carbon substrate, Table 1$)$ and the yield, $0.13 \mathrm{~mol} \mathrm{PHB} \mathrm{mol}{ }^{-1}$ carbon substrate, obtained by Quillaguamán et al. [9] in fed-batch cultures using a defined medium containing glucose as carbon source.

Results from fermentations show that Halomonas boliviensis could grow in the presence of seawater and utilize nutrients from bakery waste hydrolysate. This suggests that hydrolysate and seawater formed a nutrient complete medium for $\mathrm{PHB}$ production.

3.2. Investigation of Bakery Waste Hydrolysis. Fed-batch cultures are the most popular culture system to achieve high PHB contents. Fed-batch cultures are usually split into two stages: batch phase for cell growth and fed-batch phase for $\mathrm{PHB}$ accumulation. In Halomonas boliviensis fermentation, the medium used in batch phase should be rich in glucose and FAN in order to facilitate high cell concentration. On the other hand, medium used in fed-batch phase should be 
TABLE 2: Composition of bakery waste.

\begin{tabular}{lc}
\hline Food waste constituent & Weight specific content $\left[\mathrm{mg} \mathrm{g}^{-1}\right]$ \\
\hline Total carbohydrates & 720.4 \\
Soluble carbohydrates & 134.4 \\
Insoluble carbohydrates & 586.0 \\
Total nitrogen & 22.7 \\
Soluble nitrogen & 5.4 \\
Insoluble nitrogen & 17.4 \\
Total proteins & 129.5 \\
Soluble proteins & 30.5 \\
Insoluble proteins & 99.0 \\
\hline
\end{tabular}

rich in glucose but depleted in FAN for PHB accumulation (Figure 1) $[30,31]$. Furthermore, the medium used in fedbatch phase should be sufficiently concentrated to minimize the dilution effect due to increased volume of fermentation broth. In order to investigate which hydrolytic approaches would lead to the production of hydrolysates with targeted nutrient concentrations, bakery waste was hydrolyzed using the three methods explained in Section 2.13. The bakery waste used in experiments consisted of $720.4 \mathrm{mg} \mathrm{g}^{-1}$ total carbohydrates, $22.7 \mathrm{mg} \mathrm{g}^{-1}$ total nitrogen, and $129.5 \mathrm{mg} \mathrm{g}^{-1}$ total proteins, and is appropriate for the production of a hydrolysate that is rich in glucose and/or FAN (Table 2).

Firstly, bakery waste hydrolysis was carried out using crude enzyme extracts from Aspergillus awamori solid mashes at enzyme-to-solid ratios of 6.9 and $13.1 \mathrm{U} \mathrm{g}^{-1}$. In both cases, similar glucose concentrations of $130-150 \mathrm{~g} \mathrm{~L}^{-1}$ were found in hydrolysates after 20 hours (Figure 2(a)). However, the resultant FAN concentrations showed significant difference (Table 3, Figure 2(b)). When hydrolysis was performed at $6.9 \mathrm{U} \mathrm{g}^{-1}, 150 \mathrm{mg} \mathrm{L}^{-1}$ of FAN was obtained. When the enzyme-to-solid ratio was increased to $13.1 \mathrm{U} \mathrm{g}^{-1}$ by addition of a larger volume of crude enzyme extract, the FAN concentration also increased to $250 \mathrm{mg} \mathrm{L}^{-1}$. Aspergillus awamori is known for the secretion of both glycolytic and to a lesser extent of proteolytic enzymes [22]. Therefore, the addition of a larger volume of the crude enzyme extract led not only to increased initial glycolytic activity, but also proteolytic activity (data not shown) and consequently to higher FAN concentration in hydrolysate. This finding highlighted the possibility to adjust the resultant FAN concentration using crude enzyme extract in order to prepare a fermentation feedstock which is favourable for promoting biomass formation, while the glucose concentration remains unaffected. Figures 2(c) and 2(d) show the glucose and FAN production profiles when hydrolysis was carried out using Aspergillus awamori solid mashes. The final glucose and FAN concentrations were similar to the concentrations obtained after hydrolysis of bakery waste carried out at an enzyme-to-solid ratio of 13.1 $\mathrm{Ug}^{-1}$ (Figures 2(a) and 2(b)). Thus, there is no need to extract enzymes from fungal solid mashes prior to the use in hydrolysis.

Figure 2(e) shows glucose production profiles when hydrolyses were carried out using commercial glucoamylase at enzyme-to-solid ratios of 6.9 and $13.1 \mathrm{Ug}^{-1}$. At $13.1 \mathrm{Ug}^{-1}$ the resultant glucose concentration and yield were $200 \mathrm{~g} \mathrm{~L}^{-1}$ and $0.39 \mathrm{gg}^{-1}$, respectively, while around $170 \mathrm{~g} \mathrm{~L}^{-1}$ glucose and a slightly lower yield of $0.32 \mathrm{gg}^{-1}$ were obtained at $6.9 \mathrm{U} \mathrm{g}^{-1}$. The addition of commercial glucoamylase did not only result in highest glucose concentrations $\left(200 \mathrm{gL}^{-1}\right)$, but it also reached complete hydrolysis in less than 5 hours. This highly efficient hydrolytic performance leads to a reduced process period and eventually decreases the operating cost. The FAN concentration in the hydrolysate was low (around $100 \mathrm{mg} \mathrm{L}^{-1}$ ), as no additional FAN was released from bakery waste as compared to the control (Table 3, Figures 2(f) and 2(h)). Microbial contaminations introduced by unsterile bakery waste did not contribute to the degradation of carbohydrates and proteins, as only trace amounts of glucose $\left(<20 \mathrm{~g} \mathrm{~L}^{-1}\right)$ and FAN $\left(<80 \mathrm{mg} \mathrm{L}^{-1}\right)$ were found in the control supernatant (Figures $2(\mathrm{~g})$ and $2(\mathrm{~h})$ ). Instead, the presence of trace amounts of glucose and FAN probably originated from the water soluble carbohydrate and nitrogen fractions from bakery waste (Table 2). The fact that microbial contaminations neither degrade carbohydrates and proteins nor metabolize sugars and FAN contributes to a more controllable fermentation medium preparation process, which enables the production of a nutrient-complete fermentation feedstock with the targeted nutritional compositions and values. A medium consisting of $200 \mathrm{~g} \mathrm{~L}^{-1}$ glucose, but only $100 \mathrm{mg} \mathrm{L}^{-1}$ FAN would facilitate PHB accumulation during fed-batch phase. At the same time, due to its high glucose concentration, the dilution effect due to increasing fermentation broth volume during fed-batch cultivation can be minimized.

Apart from glucose, fructose was found in hydrolysates by the hydrolysis of sucrose in cake rich bakery wastes [15]. Although the yields of fructose were 7 to 10 times lower compared to the yields of glucose (Table 3), it was utilized by Halomonas boliviensis and contributed to cell growth and PHB formation (Figure 1(b)).

Table 3 shows that similar yields of glucose, fructose, and FAN were obtained when hydrolysis was carried out using commercial glucoamylase in seawater as solvent instead of tap water. Domínguez de María [32] reviewed the development of a seawater-based biorefinery strategy for enzymatic, fermentative, and chemocatalytic applications. In combination with food waste-based biorefinery, the use of seawater may have a strong impact on the development of efficient, low cost, and small carbon footprint PHB production processes [32].

\section{Conclusions}

In this study, bakery waste hydrolysate was evaluated as nutrient source in fermentative PHB production with seawater by Halomonas boliviensis. Moreover, the feasibility of using seawater as solvent in bakery waste hydrolysis for fermentative feedstock preparation was demonstrated. Bakery waste hydrolysates can be utilized together with seawater as fermentation media in batch and fed-batch cultures. By selecting an appropriate hydrolytic approach of 

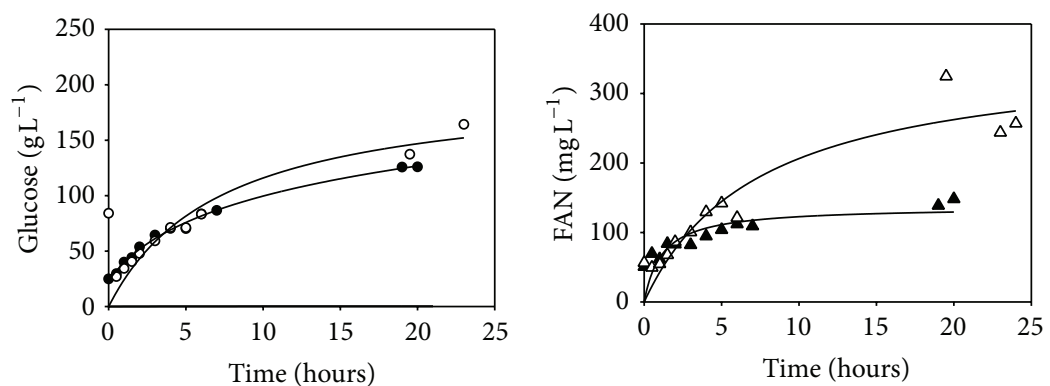

- $6.9 \mathrm{Ug}^{-1}$

$\Delta 6.9 \mathrm{Ug}^{-1}$

○ $13.1 \mathrm{Ug}^{-1}$

$\triangle 13.1 \mathrm{Ug}^{-1}$

(a)

(b)
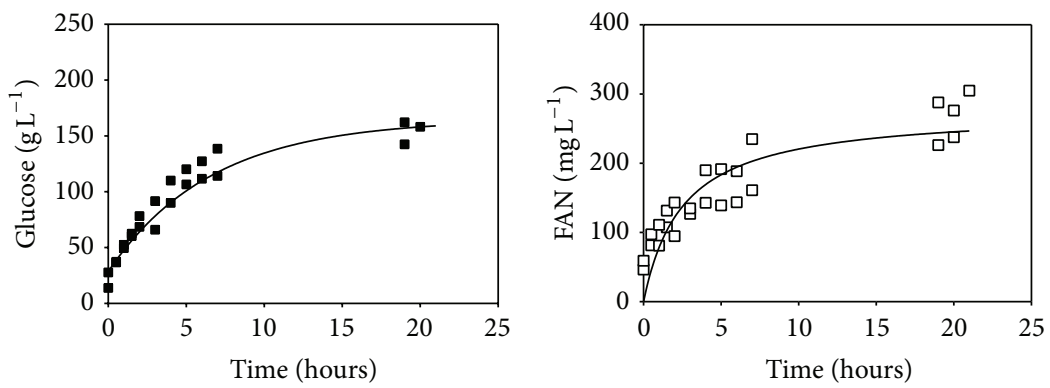

(c)

(d)
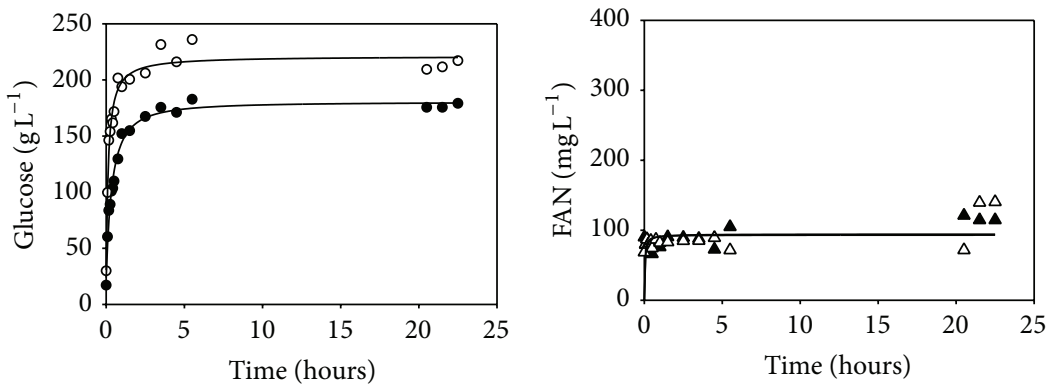

- $6.9 \mathrm{Ug}^{-1}$

○ $13.1 \mathrm{Ug}^{-1}$

$\Delta 6.9 \mathrm{Ug}^{-1}$

$\triangle 13.1 \mathrm{Ug}^{-1}$

(e)

(f)

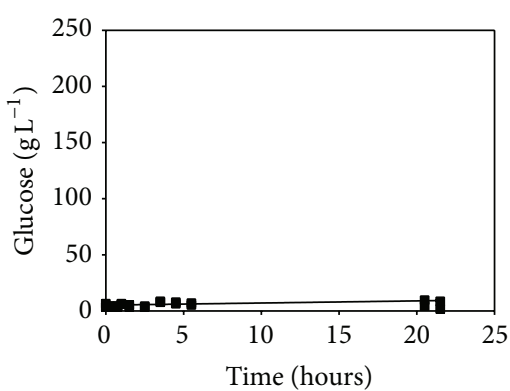

(g)

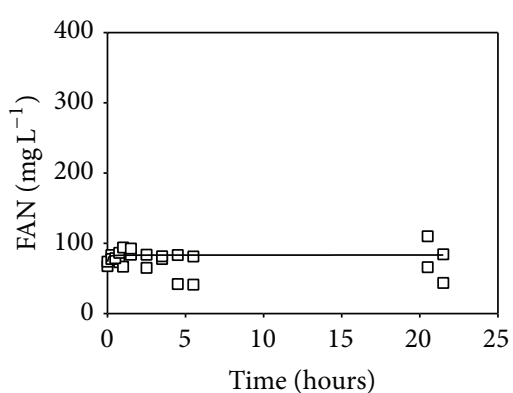

(h)

Figure 2: Change in glucose and FAN concentrations in hydrolysate during bakery waste hydrolysis using a crude enzyme extract from Aspergillus awamori solid mashes ((a) and (b)), Aspergillus awamori solid mashes directly added ((c) and (d)), commercial glucoamylase ((e) and (f)), and in a control ((g) and (h)), respectively. Hydrolyses carried out using crude enzyme extract and commercial glucoamylase were performed at enzyme-to-solid ratios of 6.9 and $13.1 \mathrm{U} \mathrm{g}^{-1}$. 
TABLE 3: Yield of glucose $\left(Y_{\mathrm{Glc}}\right)$, fructose $\left(Y_{\mathrm{Frc}}\right)$, and free amino nitrogen $\left(Y_{\mathrm{FAN}}\right)$ obtained by different hydrolytic treatments of bakery waste.

\begin{tabular}{|c|c|c|c|c|c|}
\hline Treatment & Seawater & $\begin{array}{c}\text { Enzyme-to-solid ratio } \\
{\left[\mathrm{Ug} \mathrm{g}^{-1}\right]}\end{array}$ & $\begin{array}{c}Y_{\mathrm{Glc}} \\
{\left[\mathrm{g} \mathrm{g}^{-1}\right]}\end{array}$ & $\begin{array}{c}Y_{\mathrm{Frc}} \\
{\left[\mathrm{g} \mathrm{g}^{-1}\right]}\end{array}$ & $\begin{array}{c}Y_{\mathrm{FAN}} \\
{\left[\mathrm{mg} \mathrm{g}^{-1}\right]}\end{array}$ \\
\hline \multirow{2}{*}{ Multienzyme solution } & \multirow{2}{*}{ No } & 6.9 & 0.23 & 0.02 & 0.29 \\
\hline & & 13.1 & 0.29 & 0.04 & 0.41 \\
\hline \multirow{2}{*}{ Commercial glucoamylase } & \multirow{2}{*}{ No } & 6.9 & 0.32 & 0.03 & 0.22 \\
\hline & & 13.1 & 0.39 & 0.04 & 0.26 \\
\hline Commercial glucoamylase & Yes & 1.0 & 0.28 & 0.09 & 0.36 \\
\hline Control & No & - & 0.01 & 0.01 & 0.19 \\
\hline
\end{tabular}

bakery waste, the concentration of glucose and FAN could be adjusted towards biomass or PHB formation in Halomonas boliviensis fermentation. The fed-batch fermentation strategies tested did improve the yield of $\mathrm{PHB}$, but the $\mathrm{PHB}$ content of cells was not affected. Nevertheless, the encouraging results suggested that a generic feedstock from bakery waste forms a nutrient-complete medium for microbial growth of Halomonas boliviensis and pave the way for a sustainable bioplastic production.

\section{Conflict of Interests}

The authors declare that there is no conflict of interests regarding the publication of this paper.

\section{Authors' Contribution}

Daniel Pleissner and Wan Chi Lam contributed equally.

\section{Acknowledgments}

The authors acknowledge the donation from the Coffee Concept (Hong Kong) Ltd. for the "Care for Our Planet" campaign, as well as a grant from the City University of Hong Kong (Project no. 7200248). The authors acknowledge the Innovation and Technology Fund from the Innovation and Technology Commission (ITS/353/11 and ITS/353/12) in Hong Kong.

\section{References}

[1] C. S. K. Reddy, R. Ghai, Rashmi, and V. C. Kalia, "Polyhydroxyalkanoates: an overview," Bioresource Technology, vol. 87, no. 2, pp. 137-146, 2003.

[2] K. Sudesh, H. Abe, and Y. Doi, "Synthesis, structure and properties of polyhydroxyalkanoates: biological polyesters," Progress in Polymer Science, vol. 25, no. 10, pp. 1503-1555, 2000.

[3] G. Chen and Q. Wu, "The application of polyhydroxyalkanoates as tissue engineering materials," Biomaterials, vol. 26, no. 33, pp. 6565-6578, 2005.

[4] T. Yamane, M. Fukunaga, and Y. W. Lee, "Increased PHB productivity by high-cell-density fed-batch culture of Alcaligenes latus, a growth-associated PHB producer," Biotechnology and Bioengineering, vol. 50, no. 2, pp. 197-202, 1996.

[5] W. J. Page and O. Knosp, "Hyperproduction of poly- $\beta$ hydroxybutyrate during exponential growth of azotobacter vinelandii UWD," Applied and Environmental Microbiology, vol. 55, no. 6, pp. 1334-1339, 1989.

[6] J. Tian, A. He, A. G. Lawrence et al., "Analysis of transient polyhydroxybutyrate production in Wautersia eutropha H16 by quantitative Western analysis and transmission electron microscopy," Journal of Bacteriology, vol. 187, no. 11, pp. 3825$3832,2005$.

[7] A. A. Koutinas, Y. Xu, R. Wang, and C. Webb, "Polyhydroxybutyrate production from a novel feedstock derived from a wheatbased biorefinery," Enzyme and Microbial Technology, vol. 40, no. 5, pp. 1035-1044, 2007.

[8] S. Y. Lee and H. N. Chang, "Effect of complex nitrogen source on the synthesis and accumulation of poly(3-hydroxybutyric acid) by recombinant Escherichia coli in flask and fed-batch cultures," Journal of Environmental Polymer Degradation, vol. 2, no. 3, pp. 169-176, 1994.

[9] J. Quillaguamán, T. Doan-Van, H. Guzmán et al., "Poly(3hydroxybutyrate) production by Halomonas boliviensis in fedbatch culture," Applied Microbiology and Biotechnology, vol. 78, no. 2, pp. 227-232, 2008.

[10] J. Quillaguamán, S. Hashim, F. Bento, B. Mattiasson, and R. Hatti-Kaul, "Poly $(\beta$-hydroxybutyrate) production by a moderate halophile, Halomonas boliviensis LC1 using starch hydrolysate as substrate," Journal of Applied Microbiology, vol. 99, no. 1, pp. 151-157, 2005.

[11] D. van-Thuoc, J. Quillaguamán, G. Mamo, and B. Mattiasson, "Utilization of agricultural residues for poly(3hydroxybutyrate) production by Halomonas boliviensis LCl," Journal of Applied Microbiology, vol. 104, no. 2, pp. 420-428, 2008.

[12] D. Guzmán, A. Balderrama-Subieta, C. Cardona-Ortuño, M. Guevara-Martínez, N. Callisaya-Quispe, and J. Quillaguamán, "Evolutionary patterns of carbohydrate transport and metabolism in Halomonas boliviensis as derived from its genome sequence: influences on polyester production," Aquatic Biosystems, vol. 8, no. 1, article 9, 2012.

[13] J. Choi and S. Y. Lee, "Process analysis and economic evaluation for poly(3-hydroxybutyrate) production by fermentation," Bioprocess Engineering, vol. 17, no. 6, pp. 335-342, 1997.

[14] Hong Kong SAR Environmental Protection Department, "Monitoring of solid waste in Hong Kong-waste statistics for 2011," https://www.wastereduction.gov.hk/en/materials/info /msw2011.pdf.

[15] A. Y. Zhang, Z. Sun, C. C. J. Leung et al., "Valorisation of bakery waste for succinic acid production," Green Chemistry, vol. 15, no. 3, pp. 690-695, 2013.

[16] D. Pleissner, W. C. Lam, Z. Sun, and C. S. K. Lin, "Food waste as nutrient source in heterotrophic microalgae cultivation," Bioresource Technology, vol. 137, pp. 139-146, 2013. 
[17] C. C. J. Leung, A. S. Y. Cheung, A. Y. Z. Zhang, K. F. Lam, and C. S. K. Lin, "Utilisation of waste bread for fermentative succinic acid production," Biochemical Engineering Journal, vol. 65, pp. 10-15, 2012.

[18] M. Melikoglu, C. S. K. Lin, and C. Webb, "Stepwise optimisation of enzyme production in solid state fermentation of waste bread pieces," Food and Bioproducts Processing, vol. 91, no. 4, pp. 638646, 2013.

[19] C. S. K. Lin, R. Luque, J. H. Clark, C. Webb, and C. Du, “A seawater-based biorefining strategy for fermentative production and chemical transformations of succinic acid," Energy and Environmental Science, vol. 4, no. 4, pp. 1471-1479, 2011.

[20] S. Yan, J. Yao, L. Yao, Z. Zhi, X. Chen, and J. Wu, "Fed batch enzymatic saccharification of food waste improves the sugar concentration in the hydrolysates and eventually the ethanol fermentation by saccharomyces cerevisiae H058," Brazilian Archives of Biology and Technology, vol. 55, no. 2, pp. 183-192, 2012.

[21] K. I. Kim, W. K. Kim, D. K. Seo, I. S. Yoo, E. K. Kim, and H. H. Yoon, "Production of lactic acid from food wastes," Applied Biochemistry and Biotechnology, vol. 107, no. 1-3, pp. 637-648, 2003.

[22] D. Pleissner, T. H. Kwan, and C. S. K. Lin, "Fungal hydrolysis in submerged fermentation for food waste treatment and fermentation feedstock preparation," Bioresource Technology, vol. 158, pp. 48-54, 2014.

[23] W. C. Lam, D. Pleissner, and C. S. K. Lin, "Production of fungal glucoamylase for glucose production from food waste," Biomolecules, vol. 3, no. 3, pp. 651-661, 2013.

[24] M. Melikoglu, C. S. K. Lin, and C. Webb, "Kinetic studies on the multi-enzyme solution produced via solid state fermentation of waste bread by Aspergillus awamori," Biochemical Engineering Journal, vol. 80, pp. 76-82, 2013.

[25] J. Quillaguamán, R. Hatti-Kaul, B. Mattiasson, M. T. Alvarez, and O. Delgado, "Halomonas boliviensis sp. nov., an alkalitolerant, moderate halophile isolated from soil around a Bolivian hypersaline lake," International Journal of Systematic and Evolutionary Microbiology, vol. 54, no. 3, pp. 721-725, 2004.

[26] S. Lie, "The EBC-Ninhydrin method for determination of free alpha amino nitrogen," Journal of the Institute of Brewing, vol. 79, no. 1, pp. 37-41, 1973.

[27] V. Riis and W. Mai, "Gas chromatographic determination of poly- $\beta$-hydroxybutyric acid in microbial biomass after hydrochloric acid propanolysis," Journal of Chromatography A, vol. 445, pp. 285-289, 1988.

[28] R. Wang, R. C. S. Law, and C. Webb, "Protease production and conidiation by Aspergillus oryzae in flour fermentation," Process Biochemistry, vol. 40, no. 1, pp. 217-227, 2005.

[29] J. Quillaguamán, O. Delgado, B. Mattiasson, and R. Hatti-Kaul, "Poly( $\beta$-hydroxybutyrate) production by a moderate halophile, Halomonas boliviensis LC1," Enzyme and Microbial Technology, vol. 38, no. 1-2, pp. 148-154, 2006.

[30] A. J. Anderson and E. A. Dawes, "Occurrence, metabolism, metabolic role, and industrial uses of bacterial polyhydroxyalkanoates," Microbiological Reviews, vol. 54, no. 4, pp. 450$472,1990$.

[31] S. Y. Lee, "Bacterial polyhydroxyalkanoates," Biotechnology and Bioengineering, vol. 49, pp. 1-14, 1996.

[32] P. Domínguez de María, "On the use of seawater as reaction media for large-scale applications in biorefinerie," Chemical Catalysis Catalytical Chemistry, vol. 5, no. 7, pp. 1643-1648, 2013. 

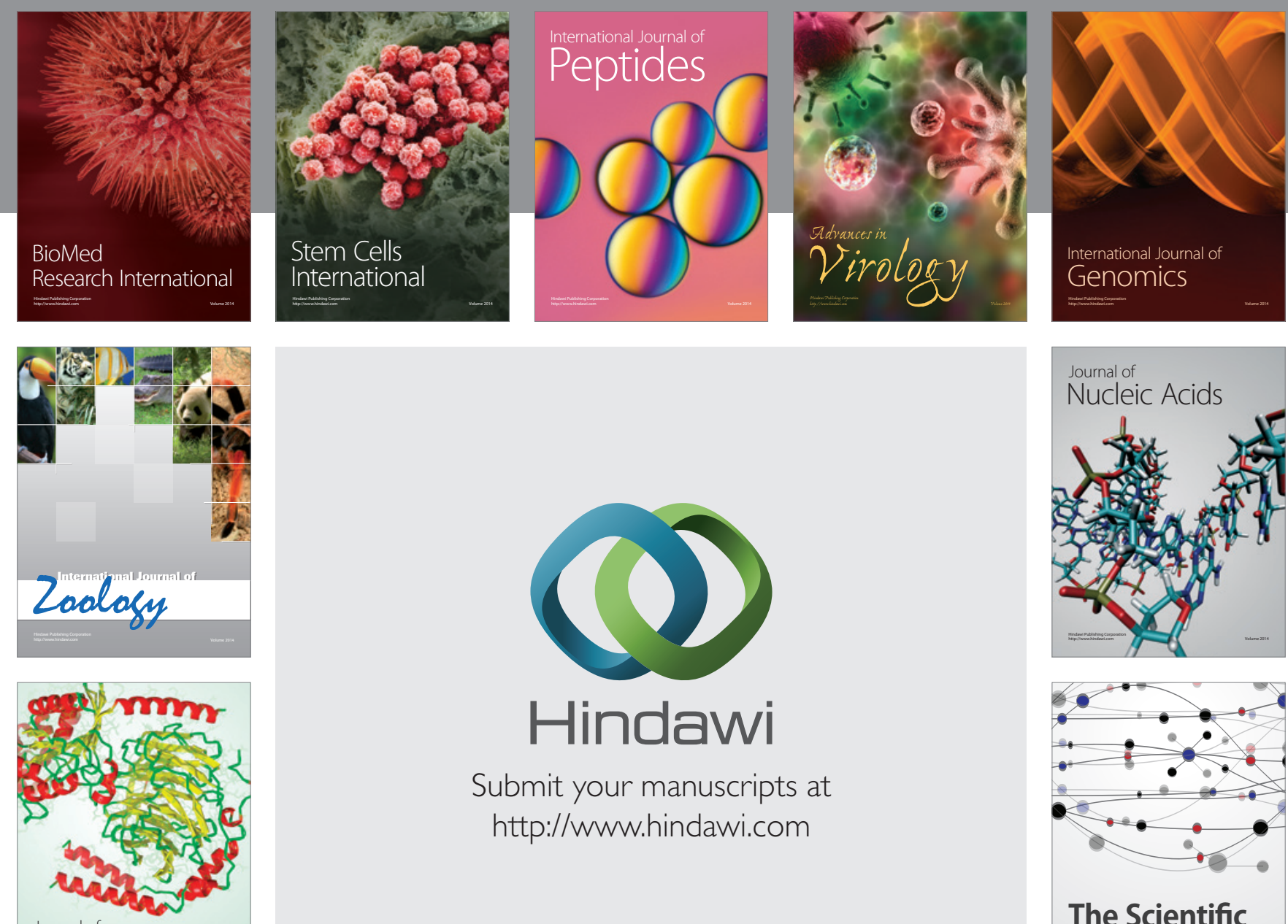

Submit your manuscripts at

http://www.hindawi.com

Journal of
Signal Transduction
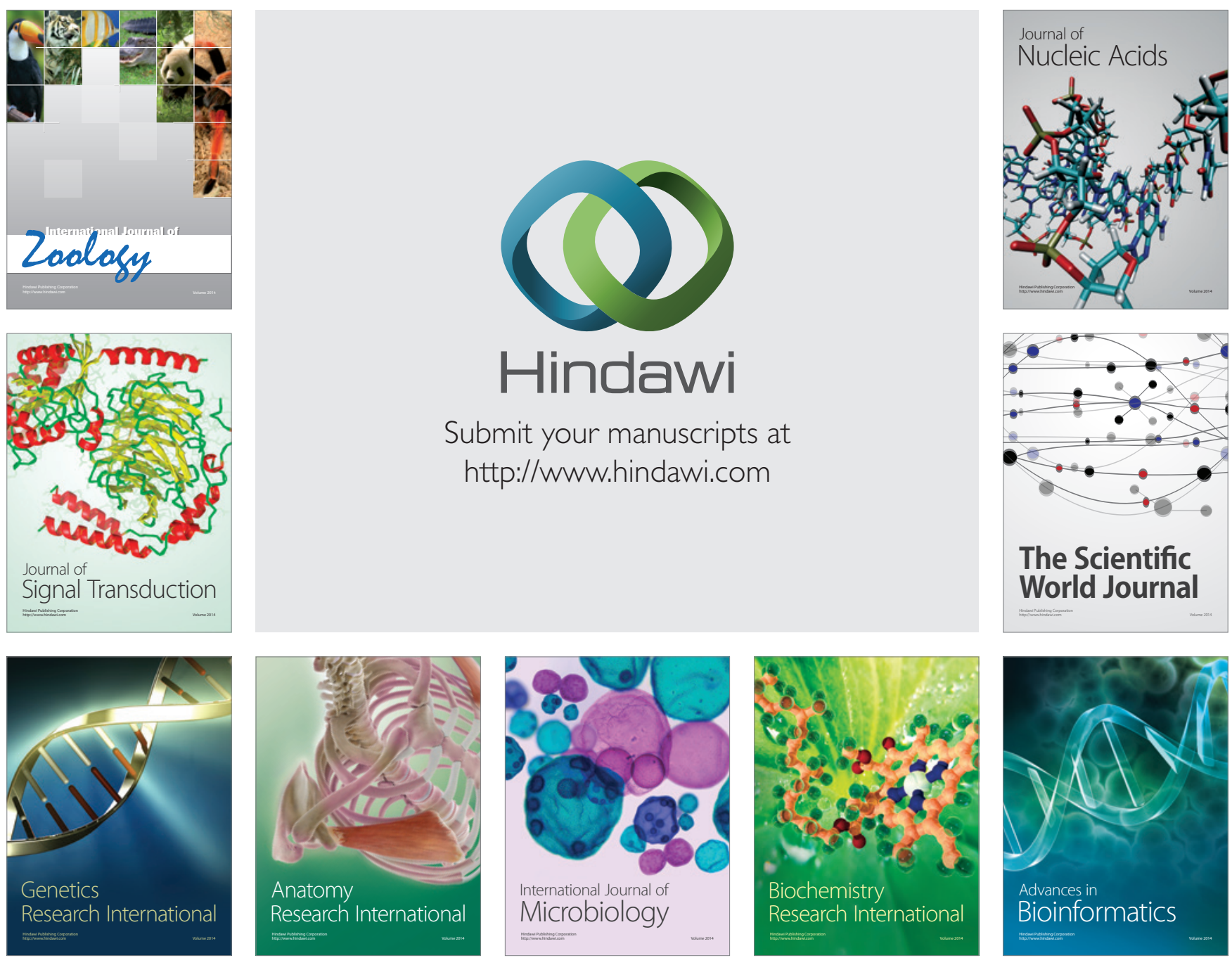

The Scientific World Journal
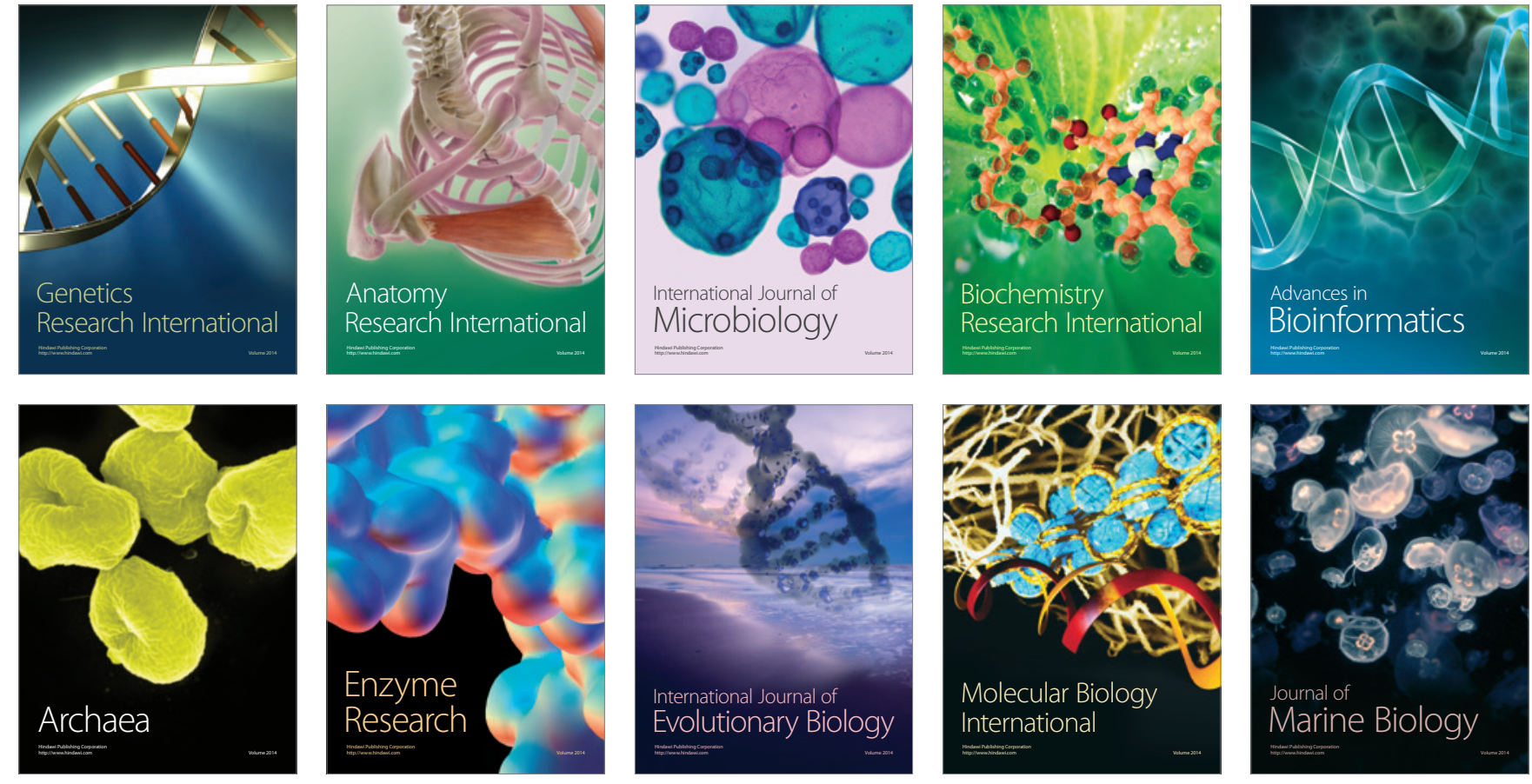